\title{
High Density Polyethylene/Libyan Kaolin Clay Nanocomposites: Effect of Clay Particle Size on Rheological, Surface and Mechanical Properties
}

\author{
Anour Shebani ${ }^{1}$, Wael Elhrari ${ }^{*}$, Abdalah Klash ${ }^{3}$, Abdelkader Aswei $^{4}$, Khalid Omran $^{5}$, \\ Abdalbary Rhab ${ }^{6}$ \\ 1,2,3,6 Polymer Research Center, Tripoli, Libya \\ ${ }^{4,5}$ Higher Institute for Comprehensive professions Al garaboulli, Libya
}

DOI: https://doi.org/10.21467/proceedings.4.20

* Corresponding author email: wael@ prc.ly

\begin{abstract}
This research work focuses on the effect of Libyan Kaolin clay particle size on the reheological, surface and mechanical properties of high density polyethylene (HDPE)/clay nanocomposites. Three polymer clay nanocomposites (PCNs) using 2 wt.\% clay with different particle size $(<75,75-150$ and $150-300 \mu \mathrm{m})$ and 2 wt.\% polyethylene grafted maleic anhydride (PE-g-MA) were prepared by melt processing method. The rheological (viscosity and melt flow rate), surface (wettability/hydrophilicity), and mechanical properties (tensile strength, elongation at break, Young's modulus, hardness and impact strength) were investigated. The obtained properties of PCNs were compared with HDPE. A better enhancement in the rheological properties properties was observed when clay particle size of $<75 \mu \mathrm{m}$ was used. It was exhibited lower viscosity and higher MFR value, which provide better processing properties in comparison to HDPE and other PCNs. PCN with clay particle size of $(75-150 \mu \mathrm{m})$ had more wettability and/or hydrophilicity than HDPE and other PCNs. Mechanical properties results showed significant improvement only in the impact properties as compared to HDPE. In short, PCN made with Libyan kaolin clay with particle size $75-150 \mu \mathrm{m}$ appears to has comparatively better overall properties in comparison to other PCNs.
\end{abstract}

Keywords: polyethylene/clay nanocomposites, particle size, rheological properties, mechanical properties, Surface properties

\section{Introduction}

Polymer nanocomposites (PNs) are termed as multiphase systems in which the nanofillers with at least one dimension in the nanoscale regime are dispersed in the polymer matrix [1]. One of the most promising PNs is the nanocomposites based on polymers and clay or clay minerals. This a special class of composites known as polymer/clay nanocomposite (PCN). PCNs have attracted great interest, because they exhibit significant improvement in polymers properties when compared with virgin polymer or conventional micro- and macro-composites

(C) 2018 Copyright held by the author(s). Published by AIJR Publisher in Proceedings of First Conference for Engineering Sciences and Technology (CEST-2018), September 25-27, 2018, vol. 2.

This is an open access article under Creative Commons Attribution-NonCommercial 4.0 International (CC BY-NC 4.0)

AiR license, which permits any non-commercial use, distribution, adaptation, and reproduction in any medium, as long as the original work is properly cited. ISBN: $978-81-936820-6-7$ 
[2]. Superior mechanical, thermal, electrical, rheological, barrier and optical properties are achievable with these nanocomposites [3-5]. PNCs are very promising materials for various applications and their demand increases in modern material industries such as aerospace, automobile, barrier materials, construction, and biomedical [6-7]. It is noteworthy, that the most important polymers that are employed in the PCNs are polyethylene, polypropylene, polyvinyl chloride, polyamide, polysulfone, polycarbonate, polyaniline, and poly(ethylene oxide). On the other hand, number of clay types have been used in PCNs include Kaolinite, Illite, Bentobite, Chlorite, and Montmonillonte.

Although, Libya rich in clay, there is no attention has been paid to use local clay as reinforcing filler for PNCs. In our previous work [8], the influence of Libyan Kaolin clay on the impact strength properties of high density polyethylene (HDPE)/clay nanocomposites was investigated. In that study, the effect of clay loading, compatibilization, and clay particle size on impact properties of HDPE/clay nanocomposites was studied. We found that the addition of Libyan Kaolin filler has resulted in an improvement in the impact strength properties of HDPE. Maximum improvement in the impact strength properties was obtained at low clay loading $(2 \mathrm{wt} . \%)$ using clay with particle size $75-150 \mu \mathrm{m}$ and $2 \mathrm{wt} . \%$ PE grafted maleic anhydride (PE-g-MA) as a compatibilizer. To gain more understanding about the influence of Libyan Kaolin clay on PCNs properties, this study aims to investigate the effect of clay particle size on rheological, surface and other mechanical properties (e.g. tensile strength, elongation at break, Young's modulus, and hardness) using HDPE/clay nanocomposites with $2 \mathrm{wt.} \%$ clay with different clay particle size and $2 \mathrm{wt} . \%$ PE-g-MA. As it was declared in our previous work [8], we hope that the obtained results will encourage Libyan scientists to start using of Libyan kaolin clay and other clays in the field of PCNs.

\section{Materials and Methods}

\section{Materials}

HDPE was used as the matrix polymer (SABIC Saudi Arabia, HDPE F00952, melt flow index $0.05 \mathrm{~g} / 10 \mathrm{~min}$ and density $\left.952 \mathrm{~g} / \mathrm{cm}^{3}\right)$. PE-g-MA prepared in our lab according to reference [9], was used as a compatibilizer. Kaolin is supplied by Industrial Research Center Tripoli (collected from Jarmah Member, Sabha city in Libya). Kaolin was sieved to remove impurities and then passed through different sieves size to get particle size of $(<75,75-150$ and 150-300 $\mu \mathrm{m})$. The plate thickness of this type of kaolin ranges from 26.5 to $40.5 \mathrm{~nm}$ [11]. $p$-Xylene (Alfa Aesar 99\%) was used to melt HDPE before compounded process.

\section{Composite Preparation}

HDPE was used as received. kaolin was dried in an air circulating oven at $85^{\circ} \mathrm{C}$ for $24 \mathrm{hr}$. The HDPE of desire amount was melt in small amount of xylene and then mixed with $2 \mathrm{wt.} \%$ kaolin and 2\% PE-g-MA in a separate bowl. The mixture then dried in an air circulating oven at $85^{\circ} \mathrm{C}$ for $24 \mathrm{hr}$. Then the final mixing was carried out using twin screw extruder (Brabender) 
High Density Polyethylene/Libyan Kaolin Clay Nanocomposites:.................................. Mechanical Properties

(L/D ratio 48) with screw speed of 70 r.p.m. at temperature from $140-190{ }^{\circ} \mathrm{C}\left(140{ }^{\circ} \mathrm{C}\right.$ for zone1, $160{ }^{\circ} \mathrm{C}$ for zone $2,170{ }^{\circ} \mathrm{C}$ for zone $3,180{ }^{\circ} \mathrm{C}$ for zone 4 , and $190{ }^{\circ} \mathrm{C}$ for zone 5 and zone 6). The extruded composites were cooled in air and then granules to small pieces. Specimens for impact strength were prepared in an injection molding (Xplore $12 \mathrm{ml}$ ) at temperature $230{ }^{\circ} \mathrm{C}$, and injection pressure of 14 bar. Details of the composites and codes are reported in Table 1.

Table 1: Composites composition and codes

\begin{tabular}{|l|l|l|l|l|l|}
\hline No & Composite name & $\begin{array}{l}\text { HDPE, wt. } \\
\%\end{array}$ & $\begin{array}{l}\text { Clay, wt. } \\
\%\end{array}$ & $\begin{array}{l}\text { Compatibilizer } \\
\text { wt. } \%\end{array}$ & $\begin{array}{l}\text { Clay's particle } \\
\text { size } \mu \mathrm{m}\end{array}$ \\
\hline 1 & HDPE & 100 & 0 & 0 & -- \\
\hline 2 & Composite 1 & 98 & 2 & 2 & $<75$ \\
\hline 3 & Composite 2 & 98 & 2 & 2 & $75-150$ \\
\hline 4 & Composite 3 & 98 & 2 & 2 & $150-300$ \\
\hline
\end{tabular}

\section{Characterization}

\section{Rheological properties}

Examples of desirable rheological properties may include: viscosity and melt flow rate (MFR). Thus, MFR and viscosity of the melt were studied using CEAST modular line melt flow models 7024 according to ASTM D 1238P. The tests were carried out at $190{ }^{\circ} \mathrm{C}$ under specified load of $5.0 \mathrm{~kg}$.

\section{Wetting properties and surface characteristics}

The measurement were carried out using Contact angle ramè-hart instrument co. model 200F4 at room temperature. $3 \mu \mathrm{l}$ volume drops of water were deposited on the surface of the HDPE and the three PCNs with a syringe. Pictures of the water drops were acquired through a digital camera positioned on a static contact angle analyzer. The $\theta$ of the contact angle was measured automatically from the image setup. Each contact angel value is an average of 5 measurements.

\section{Mechanical properties}

The tensile strength, elongation at break and young modulus were determined using SATRA tensile tester for HDPE and the three PCNs. Tensile test were performed at room temperature. Four specimens $(73 \mathrm{~mm}-4 \mathrm{~mm}-2 \mathrm{~mm})$ were tested for each sample under speed test $(100 \mathrm{~mm} / \mathrm{min})$. The hardness of molded HDPE and all composite materials were determined using a Shore D durometer RayRan in accordance with ISO 868:2003. Hardness value for each sample is an average of 8 measurements. The charpy impact test was carried out to determine the impact strength of the HDPE, and all composite materials using (CEAST Resil Impactor tester), with impact energy of $15 \mathrm{~J}$. The specimens for impact test were prepared and notched according to ASTM (D256-87). Four specimens were tested for HDPE and each composite. 


\section{$3 \quad$ Results and Discussion}

\section{Rheological properties}

Results of rheological properties of HDPE and the three PCNs are presented in Figures 1 $(a, b)$. The obtained results indicate that the particle size of Libyan Kaolin clay clearly affects the rheological properties of PCNs. Generally, the PCNs performance depends on a number of nanoparticles features such as the size, aspect ratio, specific surface area, volume fraction used, compatibility with the matrix and dispersion [12]. As shown in Figures 1 (a,b), it is apparent that the addition of Libyan Kaolin to HDPE caused decrease of the viscosity and thus an increase of the MFR in comparison to HDPE. It is known from the literature [12] that the organically clay can undergo degradation, which cause radicals formation and result chain scission. This normally reduces the molecular weight and viscosity and increases the MFR. On the other hand, the decrease viscosity of PCNs in comparison to neat polymer can be due to the reorientation of the nanoclay [13]. It is important to know that the high viscosity means a high molecular weight polymer with low MFR. Low viscosity offers better processing properties, while high viscosity is recommended for better mechanical properties. It has been reported that the addition of small amounts of nanofiller can enhance the composite properties and reduce the processing problems [14]. Kerstin et. al. [11] declared that introducing nanoparticles into the polymer might be a solution to fulfill both requirements: mechanical stability and simple processability. Therefore, it is important to describe PCNs, not only mechanically and morphologically but also rheologically as well.

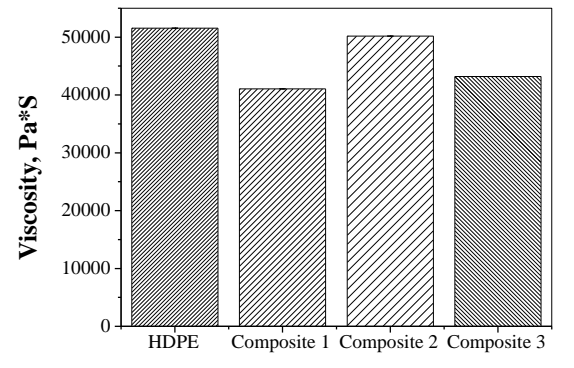

a)

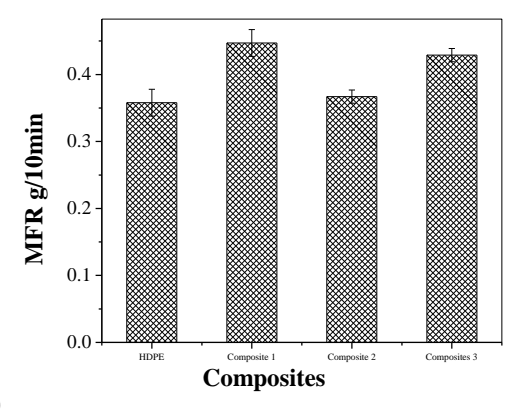

b)

Figure 1: a) Viscosity for HDPE and the three PCNs, b) MFR for HDPE and the three PCNs.

As illustrated in Figures 1 (a,b) HDPE showed to has the highest viscosity and the lowest MFR values in comparison to the three PCNs. PCN with clay particle size of $(<75 \mu \mathrm{m})$ exhibited lower viscosity and higher MFR, which provide better processing properties in comparison to HDPE and other PCNs. Whereas PCN with clay particle size of (75-150 $\mu \mathrm{m})$ showed higher viscosity and lower MFR in comparison to other PCNs. Strong interaction between filler particles and the polymer results in immobilized polymer chains on the surface of the filler, which leads to an increase in viscosity [15]. It seems that PCN with clay particle size of $(75-150 \mu \mathrm{m})$ may have the strongest interaction between the clay and HDPE in 
High Density Polyethylene/Libyan Kaolin Clay Nanocomposites:..................................... Mechanical Properties

comparison to other PCNs. Additionally, PCN with clay particle size of (150-300 $\mu \mathrm{m})$ displayed viscosity and MFR values which are intermediate between the values of the other PCNs. These results are in fair agreement with literature because MFR showed to be inversely proportional to viscosity [16]. However, such a behaviour is explained by an increase in polymer chain mobility and more free volume obtained in the nanocomposites samples [17]. According to Agboola [18], rheological behaviors of PCNs are strongly influenced by the material structure and the interfacial characteristics. Mackay et al. [19], suggested that the decrease in viscosity can be related to the free volume introduced by the clay nanoparticles. The effect of the nanoclay particles on the free volume depends on the clay/polymer interactions [9]. According to Gholizadeh et al. [20], the addition of nanoclay decreases the free volume, while opposite tendency was observed by $\mathrm{Yu}$ et.al. [21]. To clear this contradiction further investigations on the effect of the addition of nanoclays to polymer matrices are required.

\section{Wetting properties and surface characteristics}

Wetting properties and surface characteristics of HDPE and the three PCNs were studied using contact angle measurements (CAMs). CAMs are often used as an empirical indicator of wettability and interfacial tension. For polymer production where particulates or fibers are used for reinforcement, colorant, flame retardancy or stability, understanding the wetting phenomena has considerable value in relation to the material performance [22]. In practical, wettability and hydrophilicity are closely related phenomena. More wettability means more hydrophilicity. The results of the CAMs in Figure 2 revealed some information on the wettability of the HDPE and the three PCNs. Wettability and contact angle are inversely related: the lower the contact angle, the greater the wettability. The contact angle depends on several factors, such as surface energy, wettability of the surfaces, viscosity of the liquid, roughness, the manner of surface preparation, and surface cleanliness [23,24].

The HDPE represented more hydrophobicity behavior, which means less wettability property than the three PCNs because its contact angle above $90^{\circ}$ and the water droplet was tended to ball up and run off the HDPE surface. HDPE is basically a hydrophobic polymer and thus the high value of contact angle is justifiable. A surface is hydrophilic if the value of the contact angle is less than $90^{\circ}$, whereas the surface is hydrophobic if the value of the contact angle is greater than $90^{\circ}$ [30]. The contact angle of HDPE was decreased by the addition of Libyan kaolin clay in the three PCNs. This means that the wettability and/or hydrophilicity is increased for the HDPE. This is because the surface of each PCN contains some of the nanoclays [25].

The clay particle size has apparent effect on the contact angle. It decreased from 91.4 (for neat HDPE) to around 88.3 when clay with particle size of $(<75 \mu \mathrm{m})$ was added to the HDPE, while it decreased to about 85.2 when clay with particle size of $(75-150 \mu \mathrm{m})$ was added to the HDPE. It decreased finally to approximately 85.9 when clay with particle size of $(150-300 \mu \mathrm{m})$ 
was added to the HDPE. This indicates that PCN with clay particle size of (75-150 $\mu \mathrm{m})$ had more wettability and/or hydrophilicity than other PCNs. On the other hand, PCN with clay particle size $(<75 \mu \mathrm{m})$ was exhibited lower wettability and/or hydrophilicity than other PCNs. In short, the ultimate enhancement in the wettability and/or hydrophilicity which observed when clay with particle size of $(75-150 \mu \mathrm{m})$ means that the surface of HDPE became more polar in comparison to the other PCNs. This enhances the above finding and explanation. As declared above, strong interaction between filler particles and the polymer results in immobilized polymer chains on the surface of the filler, which leads to an increase in viscosity. Hence, the improvement in wettability and/or hydrophilicity of PCNs's surface can be attributed to the enrichment of the HDPE surface with nanoclays. Good wettability is often a predictor of high quality adhesive bonding. Indeed, wettability is of importance in adhesion, surface coating, water repellency, and waterproofing [26]. To our knowledge, the effect of clay's particle size on the wettability and/or hydrophilicity properties of PCNs has so far not been extensively studied.

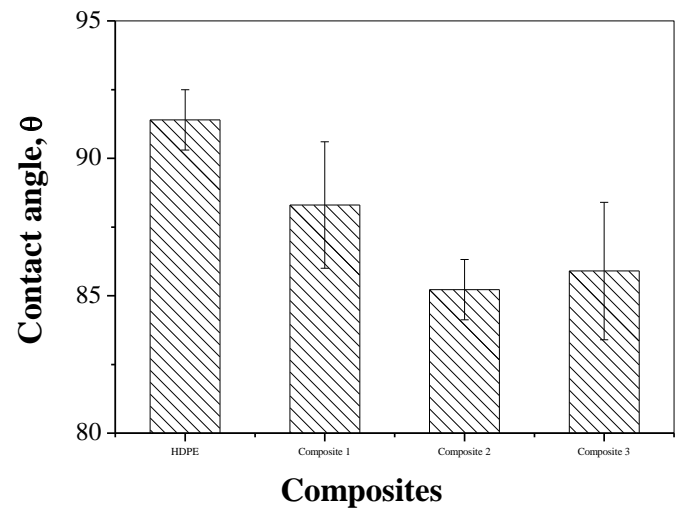

Figure 2: Contact angle for HDPE and the three PCNs.

\section{Mechanical properties}

Table 2 shows experimental data obtained for some mechanical properties of the HDPE and the three PCNs. It is important to note that the standard deviations are given in parentheses next to the values of the mechanical properties. Experimental results in Table 2 proved that clay particle size can notably affect the mechanical behavior of HDPE matrix. It was found that tensile strength, elongation at break, Young's modulus and hardness decreased, whilst impact strength increased with the addition of clay in all cases.

Table 2: Mechanical properties of HDPE and the three PCNs.

\begin{tabular}{|l|c|c|c|c|c|}
\hline \multicolumn{1}{|c|}{ Sample } & $\begin{array}{c}\text { Tensile strength, } \\
\mathrm{MPa}\end{array}$ & $\begin{array}{c}\text { Elongation at } \\
\text { break, } \%\end{array}$ & $\begin{array}{c}\text { Young's modulus, } \\
\mathrm{MPa}\end{array}$ & Hardness & $\begin{array}{c}\text { Impact strength, } \\
\text { KJ.m } \mathrm{m}^{-2}\end{array}$ \\
\hline HDPE & $29.68(3.13)$ & $2.39(0.16)$ & $794.23(2.40)$ & $60.4(1.34)$ & $12.18(1.57)$ \\
\hline Composite 1 & $19.45(1.06)$ & $2.30(0.16)$ & $734.21(1.91)$ & $58.20(20.20)$ & $25.03(4.10)$ \\
\hline Composite 2 & $19.86(1.03)$ & $2.20(0.05)$ & $760.15(1.17)$ & $57.70(0.28)$ & $39.13(5.34)$ \\
\hline Composite 3 & $22.11(1.31)$ & $2.28(0.08)$ & $599.79(5.17)$ & $52.70(0.28)$ & $38.85(4.36)$ \\
\hline
\end{tabular}

Proceedings of First Conference for Engineering Sciences and Technology (CEST-2018), vol. 2 
High Density Polyethylene/Libyan Kaolin Clay Nanocomposites:.................................... Mechanical Properties

The tensile strength of HDPE decreased approximately $34 \%$ when clay with particle size of $(<75 \mu \mathrm{m})$ was used (composite 1), while it decreased about $33 \%$ when clay with particle size of $(75-150 \mu \mathrm{m})$ was used (composite 2). The lowest decrease (about 25\%) in the tensile strength of HDPE was observed when clay with particle size of $(150-300 \mu \mathrm{m})$ was used (composite 3). In the case of PNs, most studies report the tensile properties as a function of clay content [27]. This is because the degree of crystallinity is dependent of the clay content [28]. This is important since the tensile properties are mainly dependent on the crystallinity of the polymer. Also, composite strength is very much dependent on the interface adhesion quality between the clay and polymer matrix [29].

Addition of Libyan kaolin clay caused a little reduction in the elongation at break of HDPE. The elongation at break for HDPE decreased approximately 4\%, 8\%, and 5\% when clay with particle size of $(<75 \mu \mathrm{m}),(75-150 \mu \mathrm{m})$ and $(150-300 \mu \mathrm{m})$ were used, respectively. This is because nanoclay particles are stiff materials with no elongation properties; therefore, their addition can lower composites elongation [30]. Similar findings were reported by many studies [31,32]. According to Ahmadi et. al. [32], the reduction in the elongation at break may be attributed to the fact that ductility decreases when stiffness is increased by reinforcement.

The experimental measurements of Young's modulus (also known as the elastic modulus) of the three PCNs in Table 2 illustrates that the addition of Libyan kaolin clay caused a reduction in the stiffness of HDPE matrix. This is because Young's modulus is a measure of the stiffness of a solid material. Particularly, a stiff material has a high Young's modulus and changes its shape only slightly under loads. The decrease in the Young's modulus in composite 1 and composite 2 was approximately $7.6 \%$ and $4.3 \%$, respectively. More reduction in the Young's modulus (about 24.5\%) was observed when clay with particle size of 150-300 $\mu \mathrm{m}$ was used. It is well known that the elastic modulus "Young's modulus" is a stiffness parameter which governs by the size and amount of the dispersed phase [25].

Table 2 represents also the Shore D hardness results of pure HDPE and its nanocomposites. The hardness of HDPE decreases with incorporation of nanoclay. The average value of the Shore D hardness is observed to be $\sim 60,58,57$ and 52 for pure HDPE, composite 1, composite 2 and composite 3, respectively. This means that the hardness was deceased by 3.6 $\%$ for composite 1, $4.5 \%$ for composite 2 and $12.7 \%$ for composite 3 as compared to pure HDPE. This indicates that the hardness showed to decrease with increasing the clay particle size. Hardness is found to be based on the clay loading [33].

Impact strength properties in Table 2 was published and discussed elsewhere [8]. The results show that particle size has considerable effect on the impact strength properties of HDPE/clay nanocomposite. The three PCNs showed better impact strength properties than pure HDPE. Maximum impact strength value $\left(39.125 \mathrm{KJm}^{-2}\right)$ for the composites was obtained at particle size of 75-150 $\mu \mathrm{m}$ (composites 2). Composite with particle size of 150-300 $\mu \mathrm{m}$ (composites 3) exhibited impact strength value $\left(38.851 \mathrm{KJm}^{-2}\right)$ close to that of composites 2. 
Proper particle size of kaolin at given filler content probably decreases the level of stress concentration in the composites with the resultant increase in impact strength. However, the proper particle size cannot be predicted, it depends on the particle shape, matrix and particle/matrix adhesion [25]. However, quality dispersion of nanoparticles in matrix plays key role for an improvement of impact properties of nanocomposites [34].

As shown in Figure 3, PCN made with Libyan kaolin clay with particle size 75-150 $\mu \mathrm{m}$ appears to has comparatively better overall mechanical properties in comparison to other PCNs. It can be noted from the above results that the addition of $2 \%$ of Libyan kaolin clay with different particle sizes to HDPE did not cause improvement in the mechanical properties, such as strength, elongation at break, Young's modulus and hardness. On the other hand, it has resulted in an improvement in the impact strength properties of HDPE. The properties of PCNs not only depends on the adhesion and compatibility of the organoclay with the matrix, but also on other factors such as processing conditions and clay loading. For example, George et. al. [35] studied the effect of kaolin clay particles on the mechanical, morphological and processing features of kaolin clay reinforced PS/HDPE blends and found that the tensile strength and tensile modulus of PCNs was increased with $2 \%$ clay loading, while the impact strength was increased at $3 \%$ of clay loading.

Generally, better interfacial bonding imparts better properties to a $\mathrm{PCN}$, such as tensile strength, hardness and high modulus, as well as resistance to fatigue, tear, corrosion and cracking. Since, the mechanical properties of PCNs can be altered by various factors: properties of the polymer matrix, clay particle size and morphology, particle loading and distribution, interfacial adhesion between clay and matrix, etc.. According to this it seems that the addition of $2 \%$ of Libyan kaolin clay seems to be not enough to produce the expected reinforcement in the PCNs. For example, in the case of biodegradable PCNs, most studies report the tensile properties as a function of clay loading, as mentioned above. This is because clay content effects the crystallinity which have an effect on the tensile properties. Moreover, Libyan kaolin clay appears to need special treatment to obtain clay in nanometer dimensions with narrowed particle size distribution. It is important to reveal here that nanoclays with smaller particle size distributions exhibit better dispersion in the polymer matrix. This because smaller particles have a higher surface area for a given particle loading. High surface area means more contact area available, and therefore have a higher potential to reinforce the polymer matrix. Therefore, the preparation of PCNs by using clay with smaller and more uniform particle sizes can lead to nanocomposites with better properties.

Proceedings of First Conference for Engineering Sciences and Technology (CEST-2018), vol. 2 


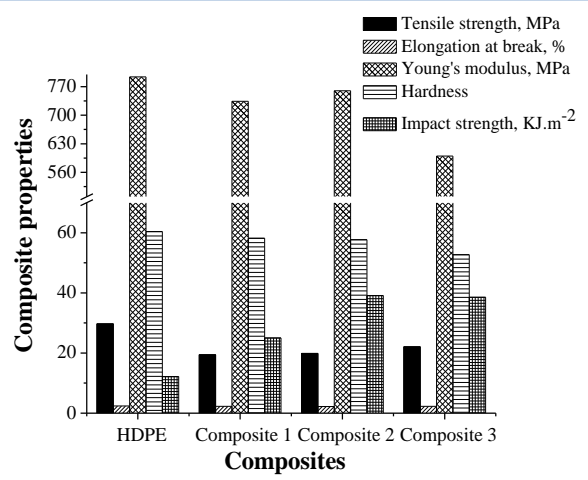

Figure 3: Comparison between the mechanical properties of HDPE and the three PCNs.

\section{Conclusions}

PCNs were produced using HDPE, 2\% Libyan kaolin clays with different particle sizes $(<75$, 75-150 and 150-300 $\mu \mathrm{m}$ ) and 2\% PE-g-MA as a compatibilizer. PCNs were prepared by meltmixing technique using mini-twin-extruder. The effects of the kaolin clay particle size on the rheological, wetting and mechanical properties PCNs were studied. PCN made with Libyan kaolin clay with particle size 75-150 $\mu \mathrm{m}$ appears to has comparatively better overall properties in comparison to other PCNs. The effects of the kaolin clay particle size on some desirable rheological properties such as viscosity and MFR was studied. HDPE showed to has the highest viscosity and the lowest MFR values in comparison to the three PCNs. PCN with clay particle size of $(<75 \mu \mathrm{m})$ exhibited lower viscosity and higher MFR value, which provide better processing properties in comparison to HDPE and other PCNs. Whereas PCN with clay particle size of $(75-150 \mu \mathrm{m})$ showed higher viscosity and lower MFR in comparison to other PCNs. Additionally, PCN with clay particle size of (150-300 $\mu \mathrm{m})$ displayed viscosity and MFR values which are intermediate between the values of the other PCNs.

Wetting properties and surface characteristics of HDPE and the three PCNs were studied using CAMs. The contact angle of HDPE decreased by the addition of Libyan kaolin clay in the three PCNs, which resulted in an improvements in the wettability and/or hydrophilicity. PCN with clay particle size of $(75-150 \mu \mathrm{m})$ had more wettability and/or hydrophilicity than other PCNs. On the other hand, PCN with clay particle size $(<75 \mu \mathrm{m})$ exhibited lower wettability and/or hydrophilicity than other PCNs. the improvement in wettability and/or hydrophilicity of PCNs's surface could be attributed to the enrichment of the HDPE surface with nanoclays.

Mechanical characterization tests including tensile strength, hardness and impact strength tests have been performed. The results showed that the addition of $2 \%$ of Libyan kaolin clay with different particle sizes to HDPE did not cause improvement in the mechanical properties, such as strength, elongation at break, Young's modulus and hardness. On the other hand, it has resulted in an improvement in the impact strength properties of HDPE. According to these results, it seems that the addition of $2 \%$ of Libyan kaolin clay not enough to produce 
the expected reinforcement in the PCNs. Moreover, Libyan kaolin clay appears to need special treatment to obtain clay in nanometer dimensions with narrowed particle size distribution. In this regard, more attention will be given to study the effect of clay loading and optimizing the clay particle size and distribution on the properties of HDPE/clay made by Libyan kaolin clay in future.

\section{Acknowledgment}

The authors would like to thank Industrial Research Centre who performed the tensile strength test.

\section{References}

[1] A. Tatyana, S. Ilya, K. József, "Polymers and related composites via anionic ring-opening polymerization of lactams: recent developments and future trends: review", Polymers, vol. 10, no. 4, pp. 357-404, 2018.

[2] K. Behzad, "Nanofiller reinforcement effects on the thermal dynamic mechanical, and morphological behavior of HDPE/rice husk flour composites", Bioresources, vol. 6, no. 2, pp. 1351-1358, 2011.

[3] M. A. Rajan, A. Ramasubbu, A. Thaddeus, V. F. Latha, T. S. Vivekanandam, S. Umapathy, "Thermal properties of PMMA/Montmorillonite clay nanocomposites", Journal of Nanoscience and Nanotechnology, vol. 6, no. 12, pp. 3993-3996, 2006.

[4] B. Xu, W. M. Huang, Y. T. Pei, Z. G. Chen, A. Kraft, R. Reuben, J. M. Hosson, Y. Q. Fu, "Mechanical properties of attapulgite clay reinforced polyurethane shape-memory nanocomposites", European Polymer Journal, vol. 45, no. 7, pp. 1904-1911, 2009.

[5] R. Sudip, Y. Q. Siew, E. Allan, D. C. Xiao, "The potential use of polymer-clay nanocomposites in food packaging", International Journal of Food Engineering, vol. 2, no. 4, pp. 1-11, 2006.

[6] D. R Paul., L. M Robeson., "Polymer nanotechnology: nanocomposites", Polymer, vol. 49, no. 15, pp. 3187-3204, 2008.

[7] G. Sagheer, K. Ayesha, M. Bakhtiar J. Saira, "Research Progress on Properties and Applications of Polymer/Clay Nanocomposite", Polymer-Plastics Technology and Engineering, vol. 55, no. 7, pp. 684-703, 2015.

[8] A. Shebani, W. Elhrari, A. Klash, A. Aswei, O. Khalid, R. Abdalbary, "Effects of Libyan kaolin clay on the impact strength properties of high density polyethylene/clay nanocomposites", International Journal of Composite Materials, vol. 6, no. 5, pp. 152-158, 2016.

[9] M. Ghaemy, S. Roohina, "Grafting of maleic anhydride on polyethylene in a homogeneous medium in the presence of radical initiators", Iranian Polymer Journal, vol. 12, no. 1, pp. 21-29, 2013.

[10] A. M. A. Shiwa, A. Hussin, "Sabha clay deposit, Libya: its mineralogy and impending industrial significance", Electronic Journal of Geotechnical Engineering, vol. 18, pp. 3803-3811, 2013.

[11] M. Kerstin, B. Elodie, L. Marcos, J. Maria, E. S. Yolanda, M. José, M. Oliver, B. Alvise, H. Steve, B. Uwe, P. Germán, J. Marius, L. Martina, S. Zuzana, C. Sara, S. Markus, "The Influence of New Hydrophobic Silica Nanoparticles on the Surface Properties of the Films Obtained from Bilayer Hybrids", Nanomaterials, vol. 7, no. 2, pp. 1-10, 2017.

[12] A. Sahar, S. Husam, "An overview of the oxidation and stabilization of polymer nanocomposites", Nanocomposites MoDeSt Workshop, Warsaw-Poland, 2013.

[13] B. Farida, K. Nadir, B., Catherine, T. Francois, E. Ruiz, "A comparative study of dispersion techniques for nanocomposite made with nanoclays and an unsaturated polyester resin", Journal of Nanomaterials, vol. 2011, pp. 1-12, Article ID 406087, 2011.

[14] M. Joshi, B. S. Butola, G. Simon, N. Kukaleva, 'Rheological and viscoelastic behavior of HDPE/octamethyl-POSS nanocomposites", Macromolecules, vol. 39, no. 5, pp. 1839-1849, 2006.

[15] J. Sapkota, "Influence of clay modification on curing kinetics of natural rubber nanocomposites", Master of Science Thesis, Tampere University of Technology, Finland, 2011.

[16] Y. Basel, "Simple rheological analysis method of spinnable-polymer flow properties using MFI tester", Indian Journal of Materials Science, vol. 2015, Article ID 790107, pp. 1-8, 2015. 
High Density Polyethylene/Libyan Kaolin Clay Nanocomposites:................................... Mechanical Properties

[17] S. H. Jin, D. K. Choi, D. S. Lee, "Electrical and rheological properties of polycarbonate/multiwalled carbon nanotube nanocomposites", Colloids and Surfaces A: Physicochemical and Engineering Aspects, vol. 313-314, pp. 242-245, 2008.

[18] O. S. Agboola, E. R. Sadiku, A. T. Adegbola, O. F. Biotidara, "Rheological properties of polymers: structure and morphology of molten polymer blends", Materials Sciences and Applications, vol. 2, no. 1, pp. 30-41, 2011.

[19] M. E. Mackay, T. T. Dao, A. Tuteja, D.L. Ho, B. V. Horn, H. Kim, and C. J. Hawker, "Nanoscale effects leading to non-einstein-like decrease in viscosity", Nature Materials. vol. 2, pp. 762-766, 2003.

[20] B. Gholizadeh, Arefazar A., and Barzin J., "Polycarbonate/polyamide 6/nanoclay ternary nanocomposite membranes: preparation, characterisation, and gas separation properties", Polymers and Polymer Composites, vol. 17, no. 3, pp. 181-187, 2009.

[21] D. Yu, H. Wang, Y. Feng, and Z. P. Fang, "Investigation of free volume, interfacial, and toughening behavior for cyanate ester/bentonite nanocomposites by positron annihilation", Journal of Applied Polymer Science, vol. 102, no. 2, pp. 1509-1515, 2006.

[22] S. P. Thomas, S. Thomas, R. Abraham, and S. Bandyopadhyay, "Polystyrene/calcium phosphate nanocomposites: Contact angle studies based on water and methylene iodide", eXPRESS Polymer Letters, vol. 2, no. 7, pp. 528-538, 2008.

[23] A. W. Adamson, and A. P. Gast, "Physical chemistry of surfaces", John Wiley \& Sons, Inc., USA, 1990.

[24] J. N. Israelachvili, 'Intermolecular and surface forces", 2ed, Academic Press, UK, 1992.

[25] A. I. Alateyah, H. N. Dhakal, and Z. Y. Zhang, "Contact angle measurement of the vinyl ester matrix nanocomposites based on layered silicate", International Journal of Materials and Metallurgical Engineering, vol. 7, no. 12, pp. 976981, 2013.

[26] C. Piao, J. E. Winandy, and T. F. Shupe, "From hydrophilicity to hydrophobicity: a critical review: part 1. wettability and surface behavior", Wood and Fiber Science, vol. 42, no. 4, pp. 490-510, 2010.

[27] W. M. Yiu, and Z. Y. Zhong, "Polymer nanocomposites", Woodhead Publishing and Maney Publishing, England, 2006.

[28] R.K. Gupta, and S.N. Bhattacharya, "Polymer-clay nanocomposites: current status and challenges", Indian Chemical Engineer, vol. 50, no. 3, pp. 242-267, 2008.

[29] S. Y. Fu, X. Feng, B. Lauke, Y. Mai, "Effects of particle size, particle/matrix interface adhesion and particle loading on mechanical properties of particulate-polymer composites", Composites: Part B, vol. 39, 933-961, 2008.

[30] E. Selver, and S. Adanur, "Processing and property relationship of polypropylene monofilaments containing nanoclay", Journal of Industrial Textiles, vol. 40, no. 2, pp. 123-137, 2010.

[31] A. Pegoretti, A. Dorigato, and A. Penati, "Tensile mechanical response of polyethylene-clay nanocomposites", eXPRESS Polymer Letters, vol. 1, no. 3, pp. 123-131, 2007.

[32] S. J. Ahmadi, H. Yudong, and W. Li, "Synthesis of EPDM/organoclay nanocomposites: effect of the clay exfoliation on structure and physical properties", Iranian Polymer Journal, vol. 13, no. 5, pp. 415-422, 2004.

[33] B. Sharma, S. Mahajan, R. Chhibber, and R. Mehta, "Glass fiber reinforced polymer-clay nanocomposites: processing, structure and hygrothermal effects on mechanical properties", Procedia Chemistry, vol. 4, pp. 39-46, 2012.

[34] R. Valek, and H. Jaroslav, "Impact properties of polymeric nanocomposites with different shape of nanoparticles", 1st Nano conference, Brno-Czech Republic, 2011.

[35] T. S. George, K. K. Asha, R. Anjana, and K. E. George, "Studies on nano kaolin clay reinforced PS-HDPE nanocomposites", Indian Journal of Advances in Chemical Science, vol. 1, no. 4, pp. 201-206, 2013. 